\title{
Effects of Pyridoxine on Improving Attention Deficit Hyperactivity Disorder Symptoms among Children under Ritalin Treatment
}

\author{
Afshin Fayazi ${ }^{1, *}$ (iD), Shahin Seifodin², Abbas Moradi ${ }^{3}$ \\ ${ }^{1}$ Assosiat Professor, Department of Pediatrics, School of Medicine, Hamadan University of Medical Sciences, Hamadan, Iran \\ 2 Pediatrician, Hamadan University of Medical Sciences, Hamadan, Iran \\ ${ }^{3}$ Instractor, Department of Community Medicine, School of Medicine, Hamadan University of Medical Sciences, Hamadan, Iran \\ * Corresponding Author: Afshin Fayazi, Department of Pediatrics, School of Medicine, Hamadan University of Medical \\ Sciences, Hamadan, Iran. Email: afshin_fay@yahoo.com
}

\begin{tabular}{|c|c|}
\hline & Abstract \\
\hline $\begin{array}{l}\text { Received: } 22.01 .2021 \\
\text { Accepted: } 13.04 .2021\end{array}$ & \multirow[b]{2}{*}{$\begin{array}{l}\text { Background and Objective: Attention Deficit Hyperactivity Disorder } \\
\text { (ADHD) is a common neuropsychological disorder among children that } \\
\text { might lead to disruption of daily activities. Therefore, this study aimed to } \\
\text { determine the effects of pyridoxine on the treatment and reduction of } \\
\text { symptoms severity in children with ADHD under Ritalin treatment. } \\
\text { Materials and Methods: This clinical trial included a total of } 50 \text { children } \\
\text { with ADHD in the age range of } 5-12 \text { years who were referred to Emam clinic } \\
\text { of Children's Neurology and Be'sat Hospital, Hamedan, Iran, and were } \\
\text { selected using a convenience sampling approach. The participants were } \\
\text { divided into two similar treatment groups. One group only received Ritalin } \\
\text { as the treatment and the second group received Pyridoxine and Ritalin } \\
\text { together. The change in the severity of the symptoms was analyzed using } \\
\text { Conners Rating Scale. } \\
\text { Results: The patients in the two treatment groups were identical in terms of } \\
\text { age and gender. The mean score of disease severity in both groups reduced } \\
\text { up to } 23.92 \text { and } 32.12 \text { units, respectively, compared to those before } \\
\text { intervention (P<0.001). In addition, there was a statistically significant } \\
\text { difference between the severity of symptoms before and after intervention in } \\
\text { both groups following the intervention (the mean scores of the severity of } \\
\text { symptoms were obtained at } 65.09 \text { and } 54.00 \text {, respectively) in children with } \\
\text { ADHD (P=0.006). } \\
\text { Conclusion: The addition of Pyridoxine tablets to the treatment diet of } \\
\text { children in the age range of } 5-12 \text { years suffering from combined symptoms } \\
\text { of ADHD led to further reduction of symptoms and an increase in the } \\
\text { effectiveness of the treatment. }\end{array}$} \\
\hline $\begin{array}{l}\text { How to Cite this Article: } \\
\text { Fayazi A, Seifodin Sh, Moradi } \\
\text { A. Effects of Pyridoxine on } \\
\text { Improving Attention Deficit } \\
\text { Hyperactivity Disorder Sym- } \\
\text { ptoms among Children under } \\
\text { Ritalin Treatment. Avicenna J } \\
\text { Clin Med. 2021; 28(1): } 5-12 \text {. } \\
\text { DOI: } 10.52547 / \text { ajcm.28.1.5 }\end{array}$ & \\
\hline & $\begin{array}{l}\text { Keywords: Attention Deficit Disorder with Hyperactivity, Methylphenidate, } \\
\text { Pyridoxine }\end{array}$ \\
\hline
\end{tabular}


do): $10.52547 /$ ajcm.28.1.5

\title{
بررسى تأثير بيريدوكسين بر بهبود علائم كودكان مبتلا به اختلال بيشفعالى / كمبود توجه تحت درمان با ريتالين
}

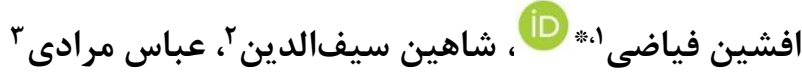 \\ ' ' دانشيار، گَروه اطفال، دانشكده يزشكى، دانشعاه علوم يزشكى همدان، همدان، ايران

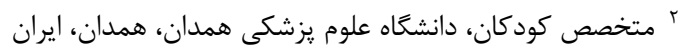

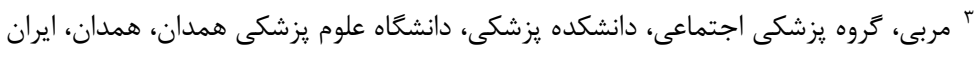

* نويسنده مسئول: افشين فياضى، كروه اطفال، دانشكده يزشكى، دانشخاه علوم يزشكى همدان، همدان، ايران. ايميل: afshin_fay@yahoo.com

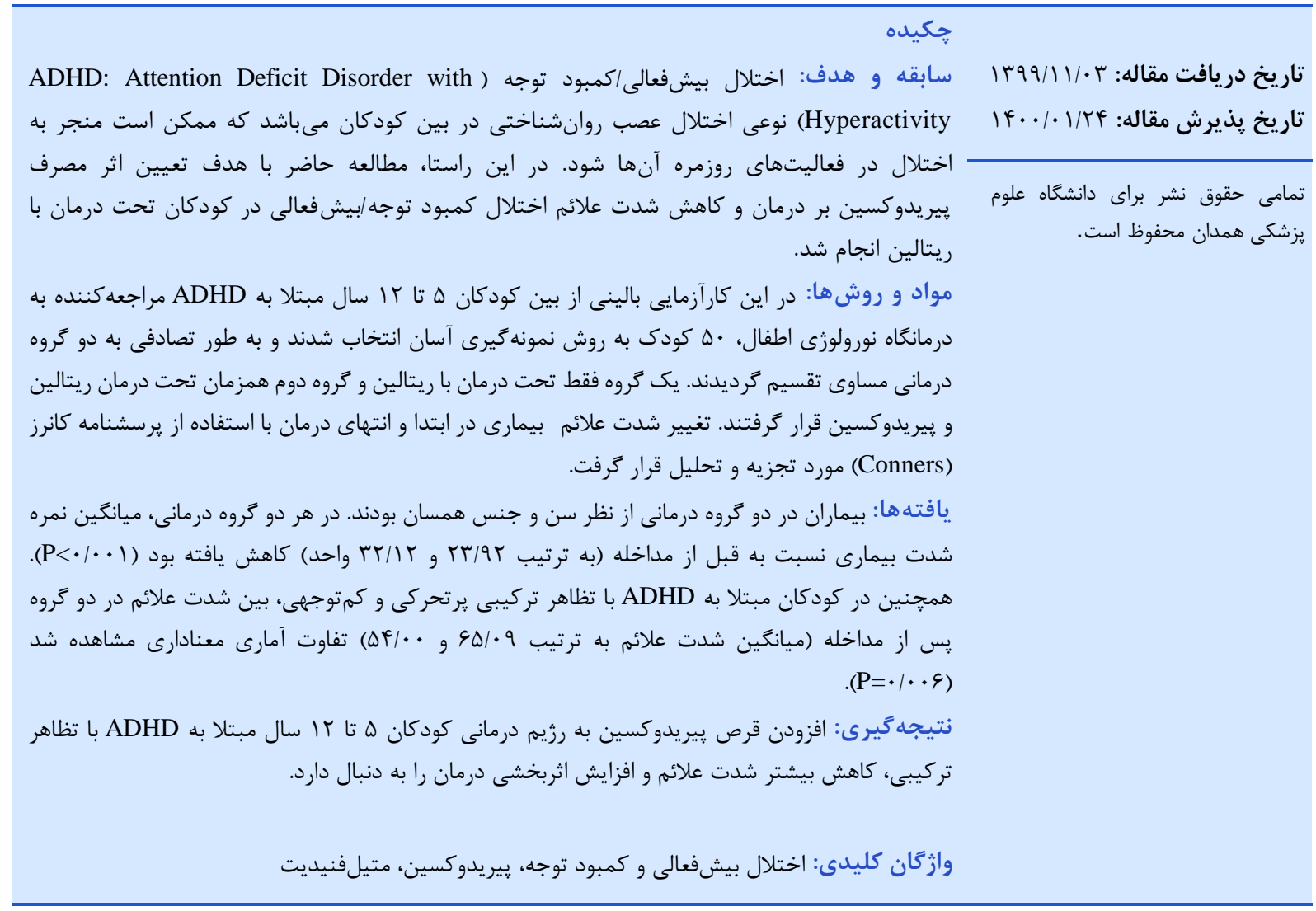

مقلدمه

كودكان مبتلا به ADHD در معرض خطر افزايشيافته

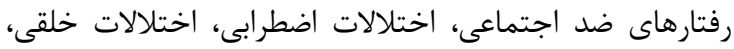

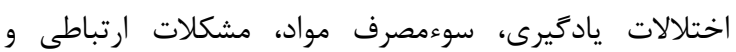

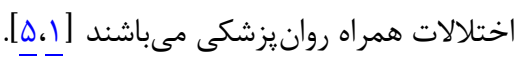

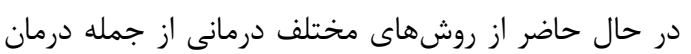

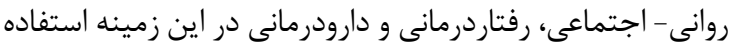

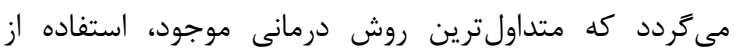

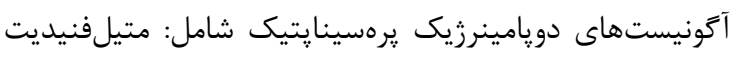
(ريتالين)، آمفتامين و دكستروآمفتامين است [عائين.
يكى از اختلالات مزمن روانيزشكى كودكان، اختلال

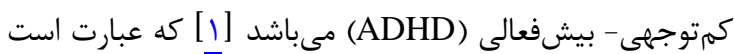

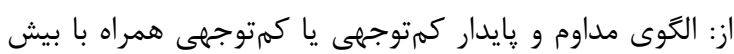

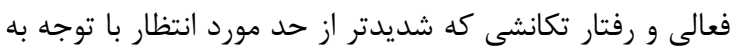
سن و سطح رشد كودى مى باشد [r]

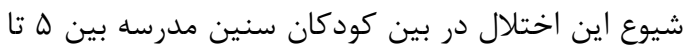

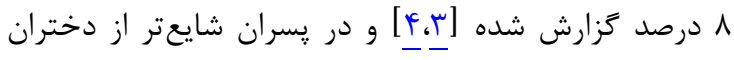

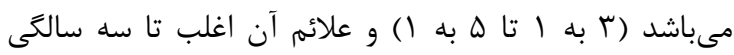

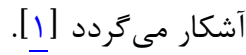


مبتلا به ADHD براساس پاسخنامه كانرز والدين و معلمان

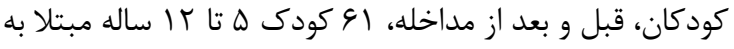

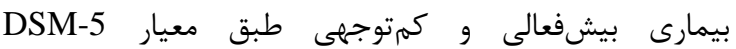
Diagnostic and Statistical Manual of Mental) (Disorders يس از توضيح كامل روند كار براى والدين و اخذ رضايت

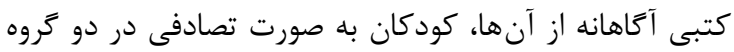

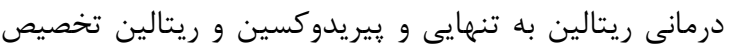
داده شدند.

در گروه اول، بيماران تحت درمان با ريتالين (متيلفنيديت)

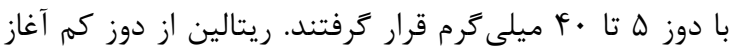

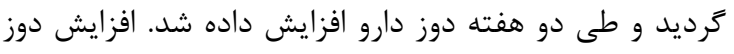
اكر باعث بهتر شدن علائم مىشد، روند افزايش ادامه مى ميافت؛

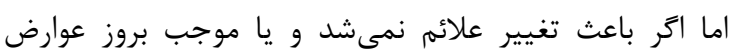

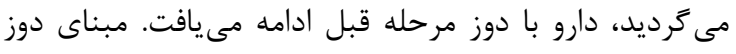

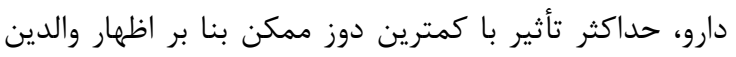

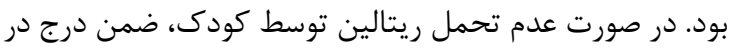
يرسشنامه، دارو قطع مى گترديد.

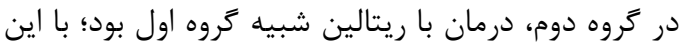

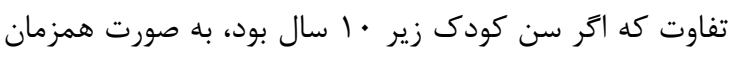

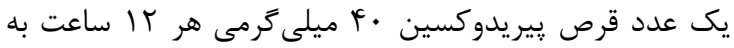

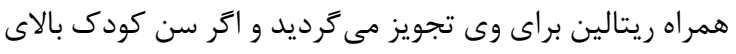

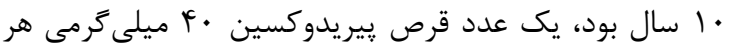

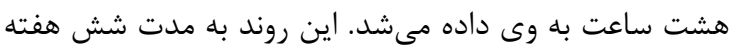

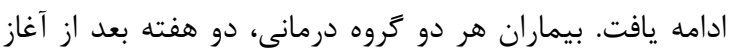

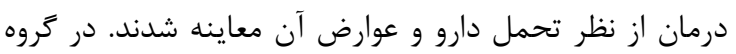

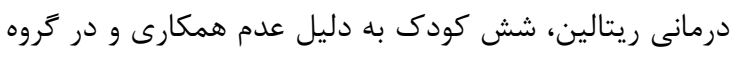

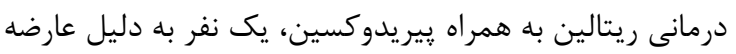

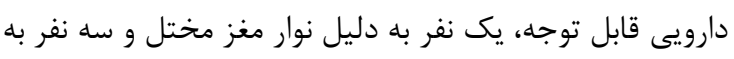
دليل عدم همكارى از مطالعه خارج شدند (شكل بل ().

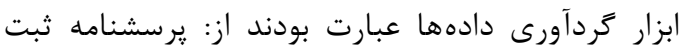

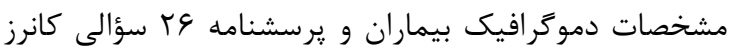

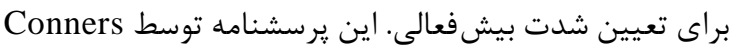

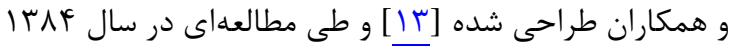

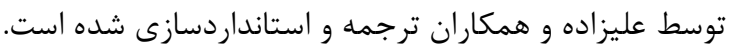

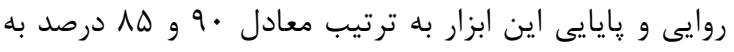

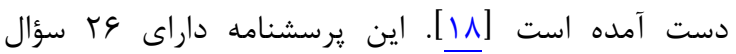

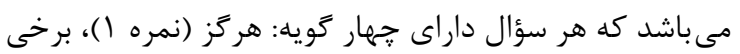

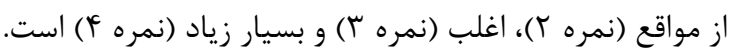

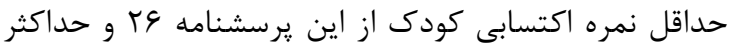

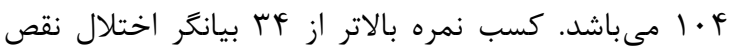

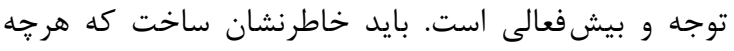

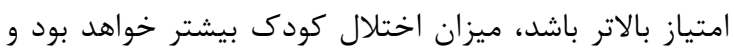

بالعكس.
ويتامين B6 (ييريدوكسين) گروهى از تركيبات با ساختمان

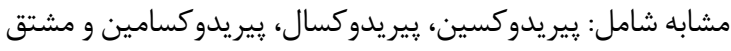

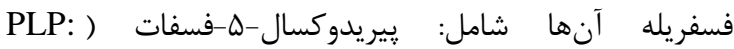

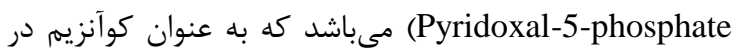
متابوليسم اسيدهاى آمينه و سنتز نوروترانسميترها، متابوليسم

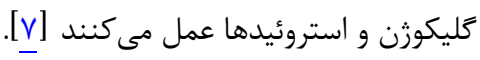

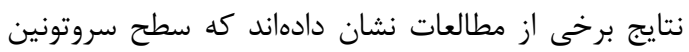

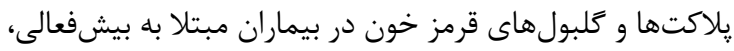

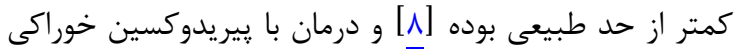
منجر به افزايش سطح سروتونين مى كردد [9، • 1].

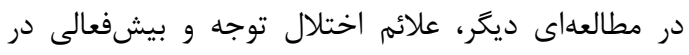

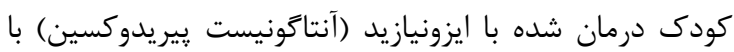
درمان با دوز بالاى بيريدوكسين بهبود يافت [11].

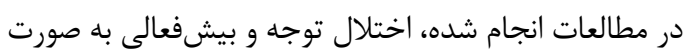

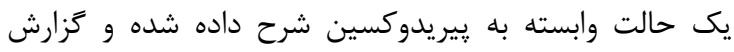

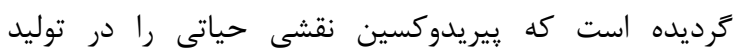

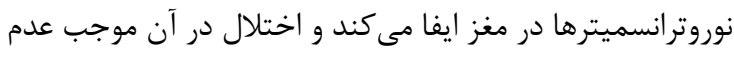

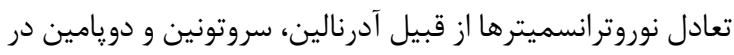

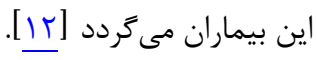

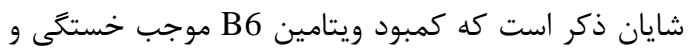

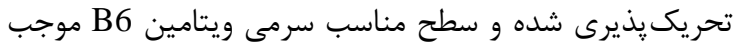

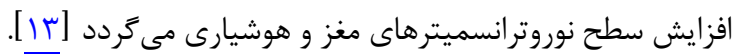

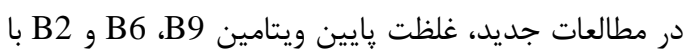

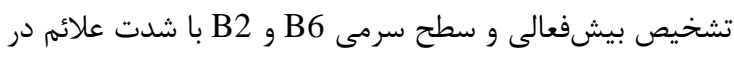

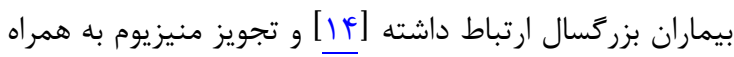

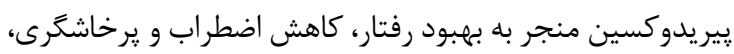

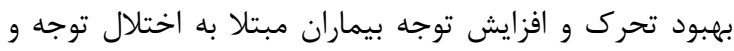

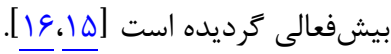
با توجه به نقش كمبود يِيريدوكسين در بد ايجاد اين بيمارى و و

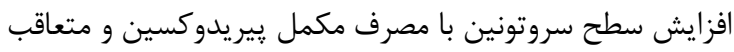

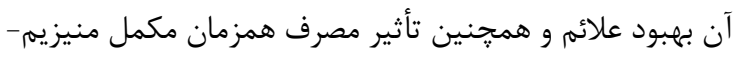

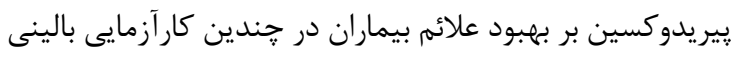

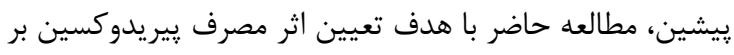

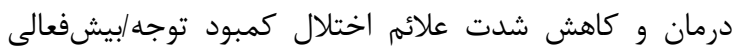
كودكان تحت درمان با ريتالين انجام شد.

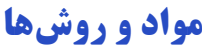

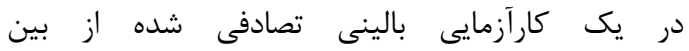
مراجعه كنند

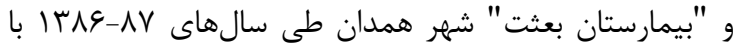

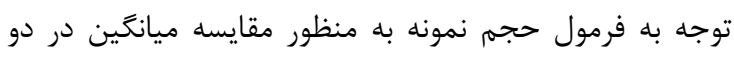

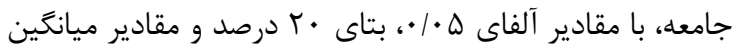

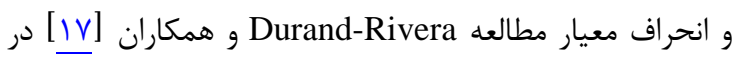
خصوص تأثير متيلفنيديت (ريتالين) بر بيشفعار مطالى دانشآموزان 


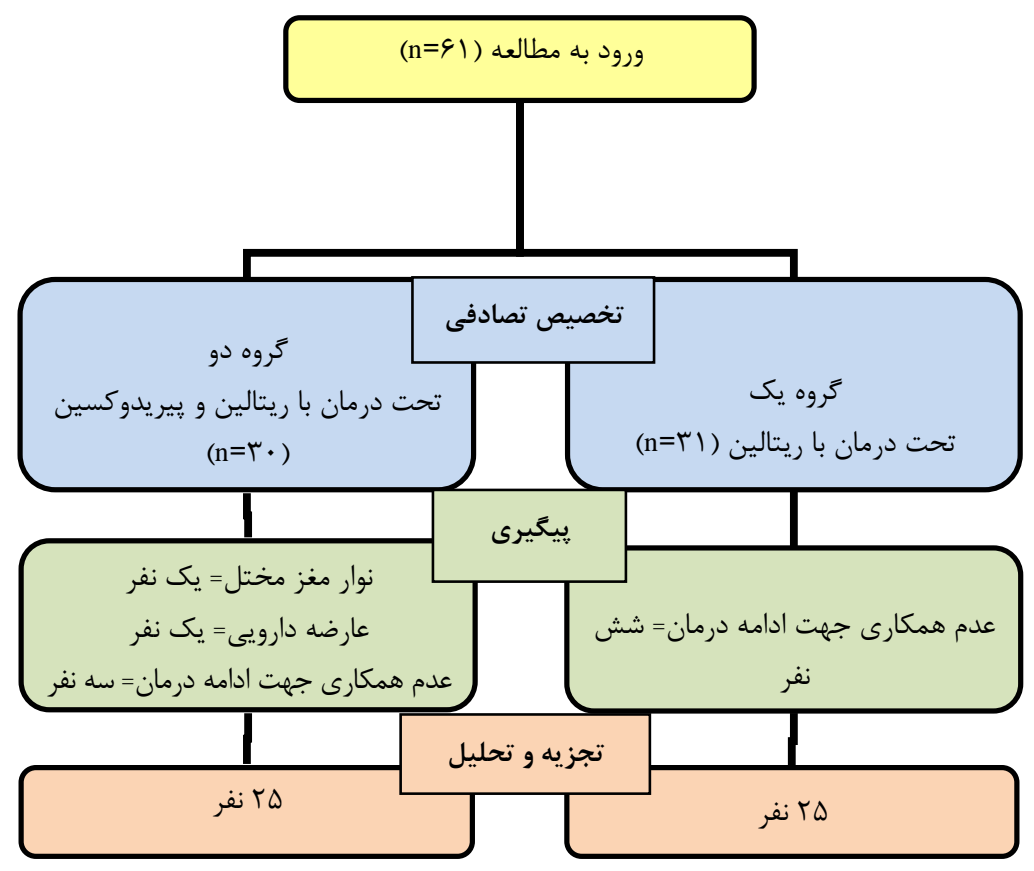

شكل ا: دياترام يِيخيرى بيماران

آزمون t زوجى استفاده گرديد. سطح معنادارى در اين مطالعه

معيارهاى ورود به مطالعه

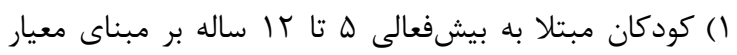

\section{بافته ها}

ميانخين سنى بيماران در گروه درمانى ريتالين و ريتالين با

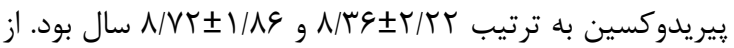

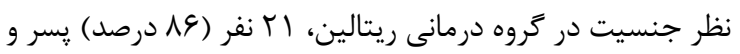

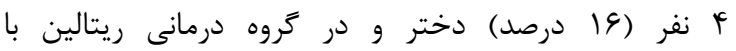

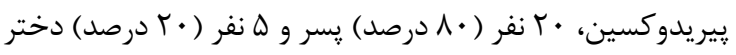

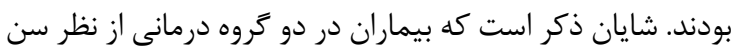

$$
\text { و جنس همسان بودند (جدول (1). }
$$

تشخيصى DSM-5

r) علائم بالينى حداقل در دو محيط جداگانه وجود داشته و

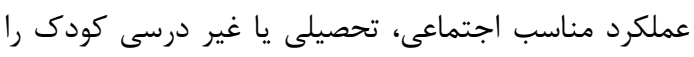
مختل كرده باشد. ץ) عدم وجود بيمارىهاى زمينهاى مختل كننده نتايج مانند عقبماندگى ذهنى، اوتيسم و كم كارى تيروئيد

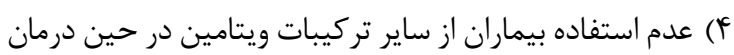

\section{معيار رهاى خروج از مطالعه}

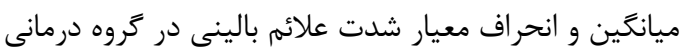

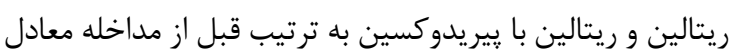

جدول ا: توزيع فراوانى اطلاعات پايه كودكان مبتلا به اختلال

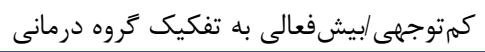

\begin{tabular}{|c|c|c|c|}
\hline معنادارى سطح & ريتالين با بيرويدوركسين دمانى & ريتالين & \\
\hline & & & جنسيت \\
\hline \multirow{3}{*}{$1 / \cdot$} & $(\Lambda \cdot / \cdot) \Gamma \cdot$ & $(\Lambda \varepsilon / \cdot) \nvdash \mid$ & يسر \\
\hline & $(Y \cdot / \cdot) \Delta$ & $(\mid 9 / \cdot)^{k}$ & دختر \\
\hline & $(1 \cdots) T \Delta$ & $(1 \cdots) r \Delta$ & مجموع \\
\hline \multirow{4}{*}{ • IOHV } & & & سن \\
\hline & T/T & $1 / 49$ & ميانگين \\
\hline & $1 / 19$ & NVY & انحراف \\
\hline & & & معيار \\
\hline
\end{tabular}

() بيمارانى كه در حين درمان به دليل ايجاد عوارض، جزء موارد معارد

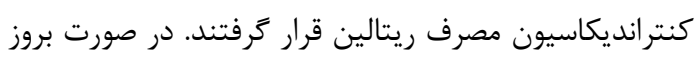

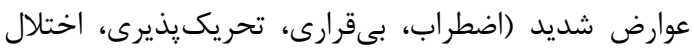

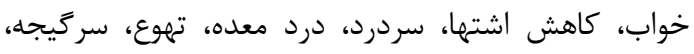

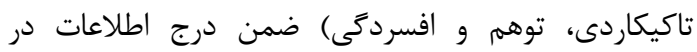

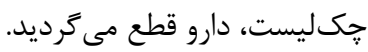

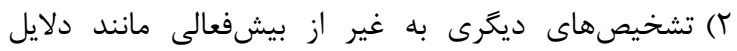

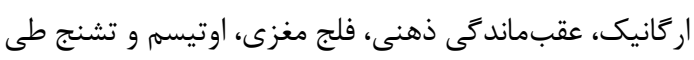
درمان براى بيمار مطرح مى كرديد.

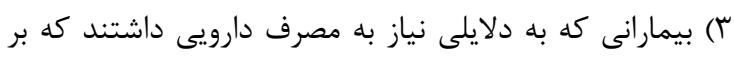
شدت بيشفعالى تأثير مى حذاشت (مانند رسيريدون).

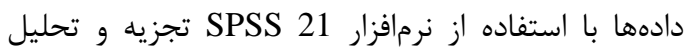

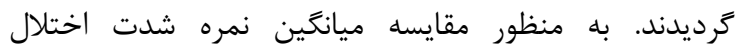

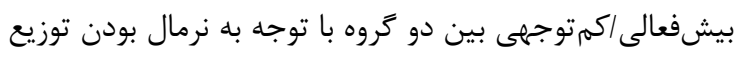

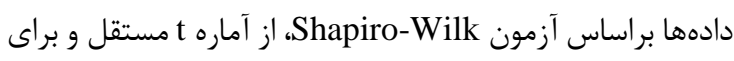

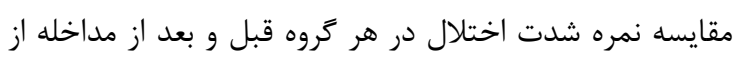


جدول ب: مقايسه شدت علائم اختلال كمبود توجه/بيشفعالى در هر دو گروه درمانى ريتالين به تنهايى و ريتالين با پيريدوكسين بر حسب معيار كانرز

\begin{tabular}{|c|c|c|c|}
\hline \multirow{2}{*}{ سطح معنادارى } & \multicolumn{2}{|c|}{ شدت علائم } & \multirow{2}{*}{ تروه درمانى } \\
\hline & انحراف معيار & ميانَين & \\
\hline \multirow{3}{*}{ - ITKA } & & & قبل از مداخله \\
\hline & $\mid F / F \Delta$ & マ৭/৭४ & ريتالين \\
\hline & $9 / \pi$. & $\wedge F / 19$ & ريتالين با ٍِيريدوكسين \\
\hline \multirow{3}{*}{.1194} & & & بعد از مداخله \\
\hline & IT/AS & $\Delta q / \cdot \mathcal{F}$ & ريتالين \\
\hline & V/^६ & $\Delta r / \cdot F$ & ريتالين با پيريدوكسين \\
\hline
\end{tabular}

جدول ب: مقايسه شدت علائم اختلال كمبود توجه بيشفعالى، قبل و بعد از مداخله در هر دو گروه درمانى ريتالين به تنهايى و ريتالين با ٍِيريدوكسين بر حسب معيار كانرز

\begin{tabular}{|c|c|c|c|}
\hline \multirow{2}{*}{ سطح معنادارى } & \multicolumn{2}{|c|}{ زمان ارزيابى } & \multirow{2}{*}{ كروه در مانى } \\
\hline & بعد از مداخله & قبل از مداخله & \\
\hline$<\cdot|\cdot \cdot|$ & $\Delta \varphi / \cdot F$ & マ१/१९ & ريتالين به تنهايى \\
\hline$<\cdot 1 \cdot \cdot 1$ & $\Delta r / \cdot \Delta$ & $\Lambda F / 19$ & ريتالين با پيريدوكسين \\
\hline
\end{tabular}

اما بين كودكان مبتلا به اختلال كمتوجهى ابيشفعالى در دو كروه

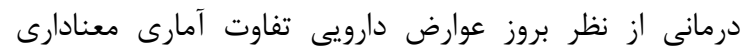

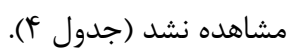

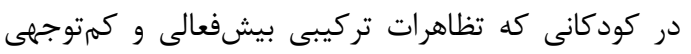

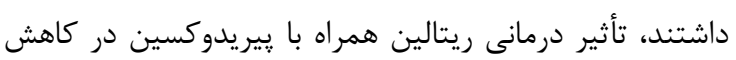

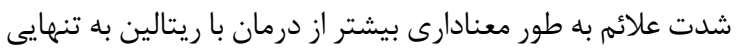

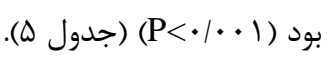

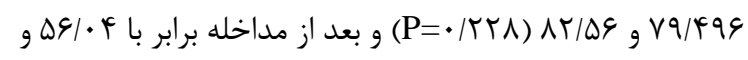
( $)$ (P= بود (P)

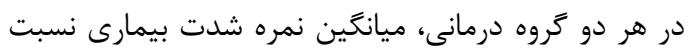

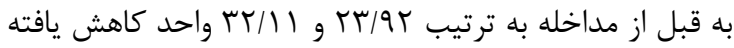

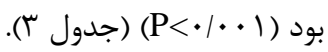

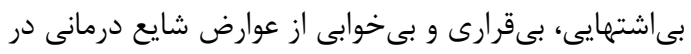

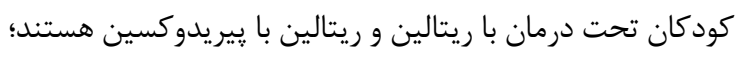

\begin{tabular}{|c|c|c|c|}
\hline سطح معنادارى & ريتالين با بير يدوكسين & ريتالين & عوارض \\
\hline $1 / \cdots *$ & $(F N / \cdot) \mid r$ & $\left(\mathrm{FN}^{\mathrm{N}} \cdot\right) \operatorname{Ir}$ & بى اشتههايى \\
\hline . & $(r \cdot / \cdot) \Delta$ & $(Y Y / \cdot) G$ & بىقرارى \\
\hline$\cdot / / \Delta V *$ & $(r N /){ }^{\prime}$ & $(\mid Y / \cdot) r$ & بى خوابى \\
\hline$\cdot 19 \cdot 9 * *$ & $(\mid r / \cdot) r$ & $(\boldsymbol{F} / \cdot))$ & سردرد \\
\hline $1 / \cdots * * *$ & $(\boldsymbol{f} / \cdot))$ & $(\boldsymbol{q} / \cdot)) 1$ & كاهش وزن \\
\hline$\cdot \mid \Delta \Delta Y * * *$ & $(\boldsymbol{F} / \cdot))$ & $(N / \cdot) r$ & ناراحتى توارشى \\
\hline $1 / \cdots * * *$ & $(f / \cdot))$ & $(\cdot) \cdot$ & تهوع \\
\hline $1 / \cdot \cdots * * *$ & $(\boldsymbol{c} / \cdot)) 1$ & $(\cdot) \cdot$ & ساير \\
\hline
\end{tabular}

جدول F: مقايسه فراوانى (درصد) بروز عوارض در كودكان مبتلا به اختلال كمبود توجه/بيشفعالى در گروه درمانى ريتالين به تنهايى و ريتالين با بيريدوكسين

جدول ه: مقايسه ميانكين (انحراف معيار) نمره شدت علائم پِّ از مداخله در كودكان مبتلا به اختلال كمبود توجه/بيشفعالى در تروه درمانى ريتالين

\begin{tabular}{|c|c|c|c|c|}
\hline معنادارى سطح & مانى ريتالين با بير يدوكسين & ريتالين & تعداد & نوع اختلال غالب \\
\hline$\cdot / f \Delta \varphi$ & $(V / 1 I)$ FN/A9 & $(9 / /)) F D / A V$ & $9-\wedge$ & بى توجهى \\
\hline$\cdot 11 \cdots$ & $(1 \cdot / \cdot V) \Delta 1 / \cdots$ & $(I r / V \varepsilon) \Delta r / \cdot \cdot$ & $9-4$ & بيشفعالى \\
\hline $.1 \cdot .9$ & $(V / T r) \Delta F / \cdots$ & $(V / 9 \cdot) 9 \Delta / \cdot 9$ & $|r-1|$ & بيشفعالى و بى توجهى \\
\hline
\end{tabular}

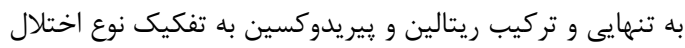


شدت علائم بيمارى داشتند.

19v9 و همكاران نيز مطالعهاى را در سال Coleman ״يرامون مقايسه يِيريدوكسين، متيلفنيديت و يلاسبو در ارتباط با شش بيمار مبتلا به سندرم بيش فيشالى بيدي انجام دادند. نتايج حاصل

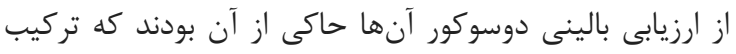

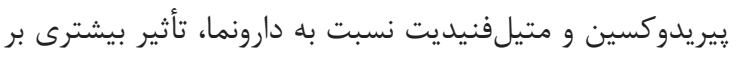

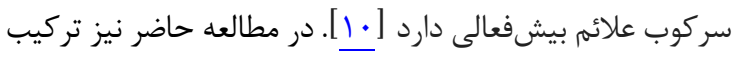

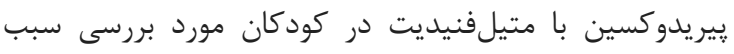

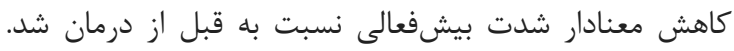

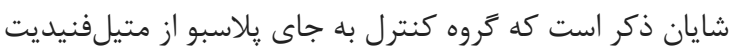

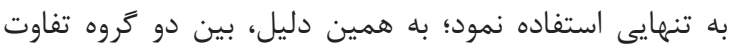
معنادارى مشاهده نتخرديد.

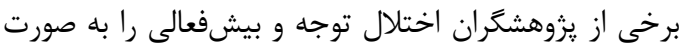

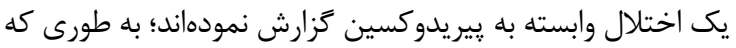

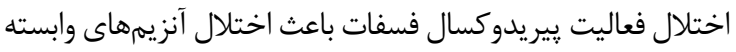

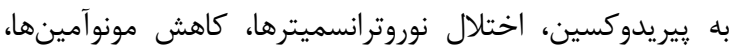

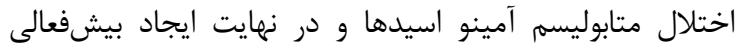

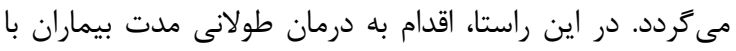

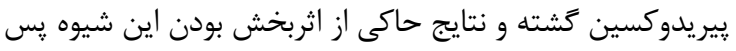

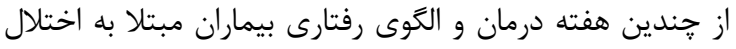

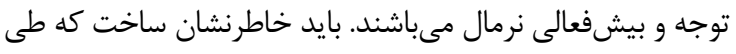

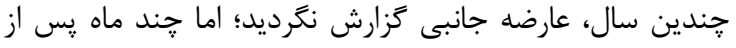

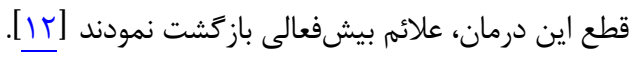

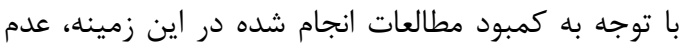

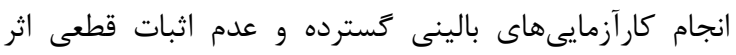

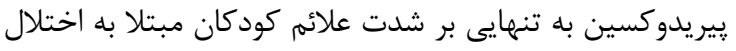

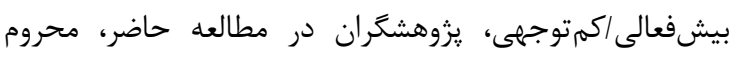

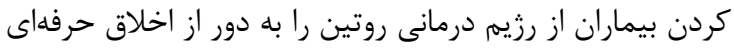

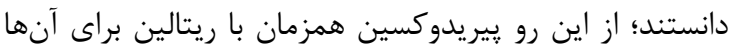

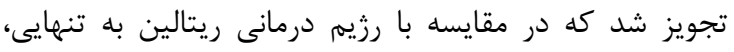

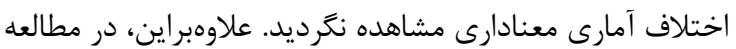

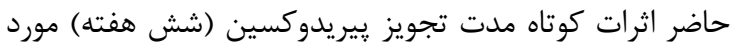

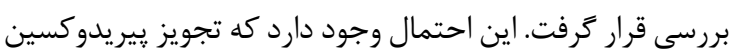

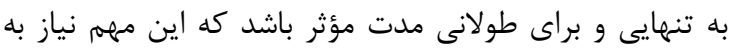
تحقيق بيشتر دارد.

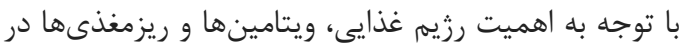

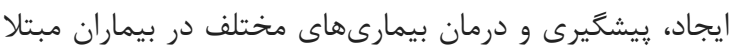

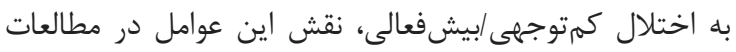

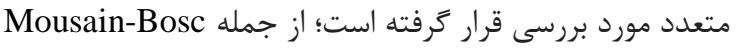

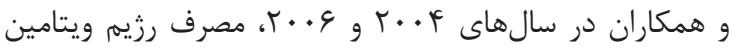
B66 و منيزيمم را در كاهش علائم بيشفعالى بررسى نمانى نمودند. نتايج

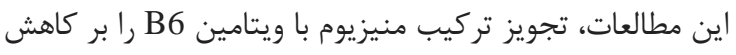

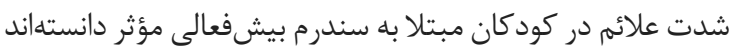

در مطالعه حاضر در هر دو گروه درمانى ريتالين و ريتالين

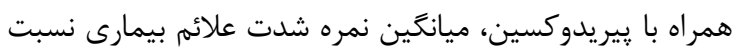

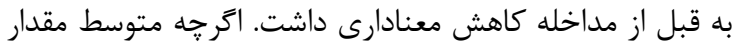
كاهش نمره شدت علائم در بيماران دريافت كننده ريتالين همراه ماهد داه

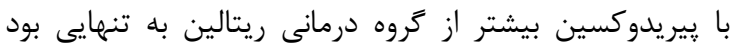

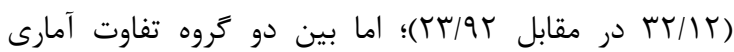
معنادارى مشاهده نشد. با زروهبندى بيماران از نظر نوع اختلال

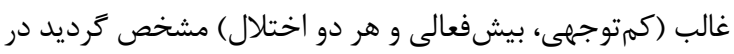

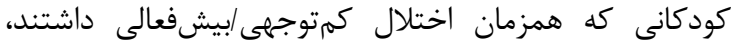

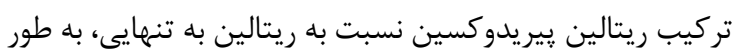

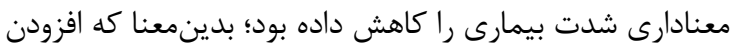

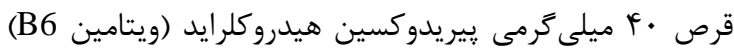

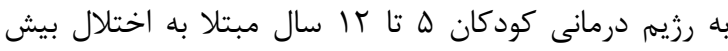

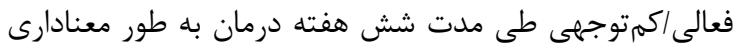

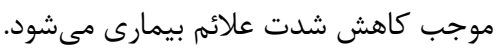

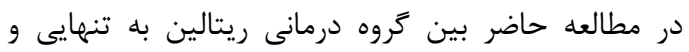

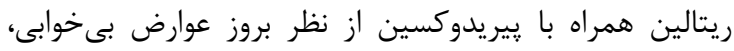

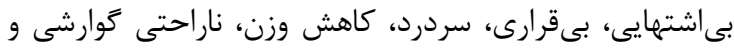
تهوع اختلاف آمارى معنادارى مشاهده نكرديد.

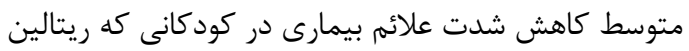

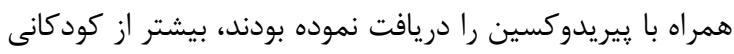

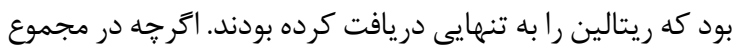

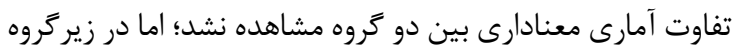

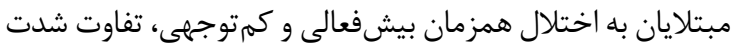

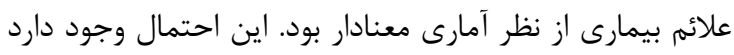

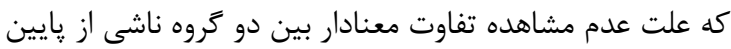
بودن حجم نمونه به دليل محدوديتهاى اجرايى طرح و يا تأثير

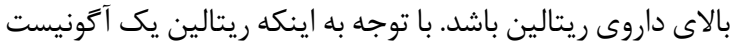

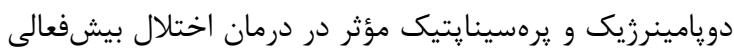

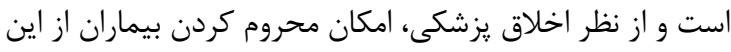

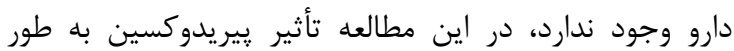
ملموس و معنادار قابل اندازهَيرى نبود. در مطالعه صورت گرفته توسط Brenner و همكاران در ارتباط نداط ندود

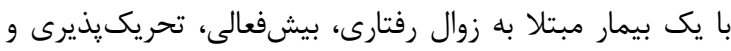

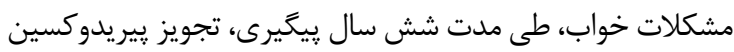

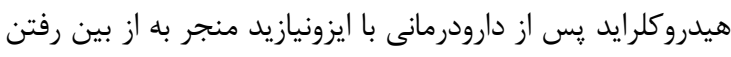

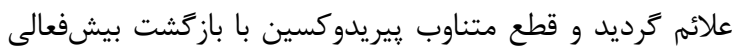

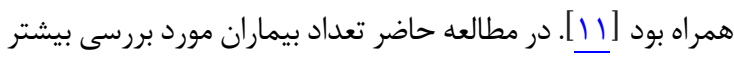

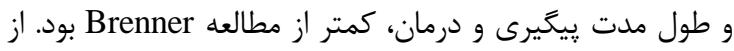

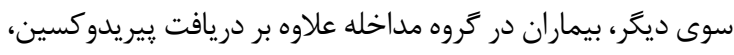

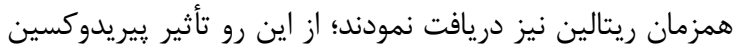

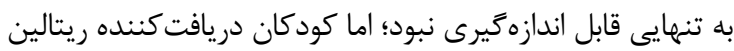

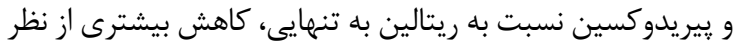




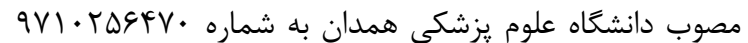

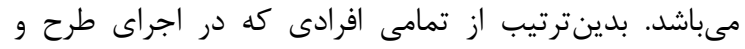

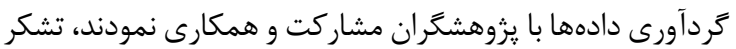
و قدردانى مى

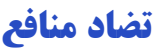
نتايج اين مطالعه با منافع نويسندًان تعارض ندارد.

\section{ملا حظات اخلاقى}

اين مطالعه داراى تأييديه از كميته اخلاق در يزوهش دانشكاه

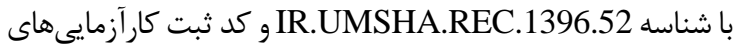

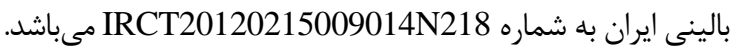

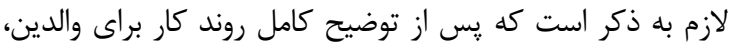

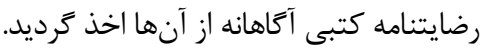

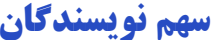

نويسنده اول (يزوهشگر اصلى): مسئول مكاتبات، طرح

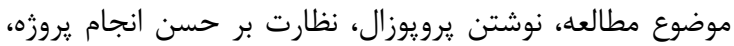

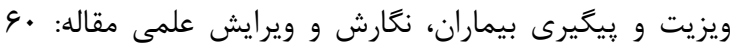

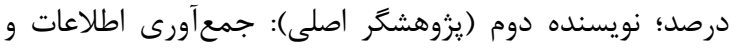

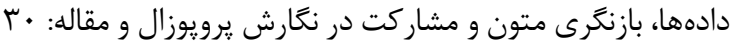

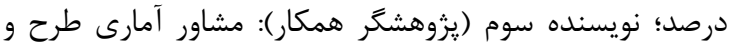
تدوين

\section{حماثت مالكى}

اين مطالعه از سوى معاونت تحقيقات و فناورى دانشگاه علوم

$$
\text { يزشكى همدان يشتيبانى مالى شده است. }
$$

\section{REFERENCES}

1. Travis F, Grosswald S, Stixrud W. ADHD, brain functioning, and transcendental meditation practice. Mind Brain $J$ Psychiatr. 2011;2(1):73-81.

2. Sadock BJ, Sadock VA. Kaplan and Sadock's synopsis of psychiatry: behavioral sciences/clinical psychiatry. Philadelphia: Lippincott Williams \& Wilkins; 2011.

3. Grizenko N, Shayan YR, Polotskaia A, Ter-Stepanian M, Joober R. Relation of maternal stress during pregnancy to symptom severity and response to treatment in children with ADHD. J Psychiatry Neurosci. 2008;33(1):10-6. PMID: 18197267

4. Linnet KM, Dalsgaard S, Obel C, Wisborg K, Henriksen TB, Rodriguez A, et al. Maternal lifestyle factors in pregnancy risk of attention deficit hyperactivity disorder and associated behaviors: review of the current evidence. Am J Psychiatry. 2003;160(6):1028-40. PMID: 12777257 DOI: 10.1176/appi.ajp.160.6.1028

5. Amiri S, Fakhari A, Golmirzaei J, Mohammadpoorasl A, Abdi S. Tourette's syndrome, chronic tics, and comorbid attention deficit/hyperactivity disorder in elementary students. Arch Iran Med. 2012;15(2):76-8. PMID: 22292574

6. Singh P, Patil Y, Rale V. Biosurfactant production: emerging trends and promising strategies. J Appl Microbiol. 2019; 126(1):2-13. PMID: 30066414 DOI: 10.1111/jam.14057

7. Ohadi M, Forootanfar H, Rahimi HR, Jafari E, Shakibaie M, Eslaminejad T, et al. Antioxidant potential and wound healing activity of biosurfactant produced by Acinetobacter
و بيان نمودهاند كه قطع رزيم درمانى با بازَّشت علائم همراه بوده

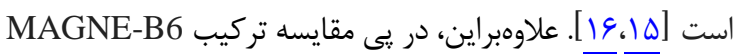
با مولتىويتامين مشخص شده است كه MAGNE-B6 نسبت بـ به مقابسه تركيب

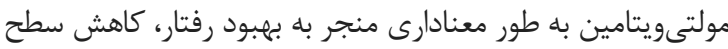

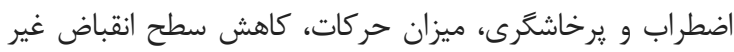

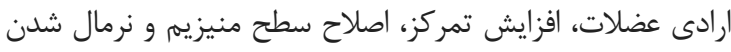

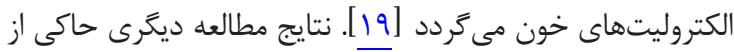

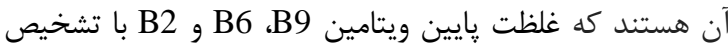
بيشفعالى و سطح سرمى B6 و B2 با شدت على علائم اين بيماران

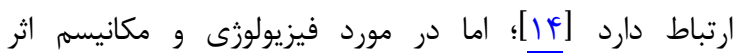

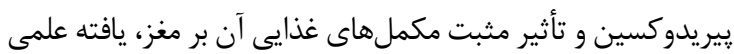
ديكر اين است كه amma-Aminobutyric acid) GABA) يك آمينو اسيد مىباشد كه منجر به آرامش و كاهش استرس مى آشود.

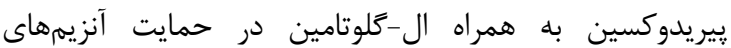

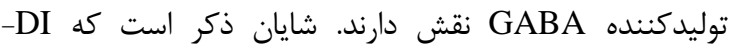
فنيل آمين باعث افزايش مصرف يروتئينها، استيل-ال-كارنيتين و

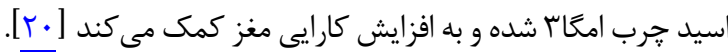

نتيجه كيرى

افزودن بيريدوكسين به ريتالين به منظور درمان كودكان ه

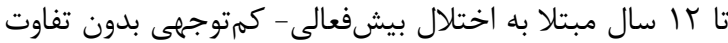
در بروز عوارض موجب كاهش بيشتر شدت علائم نسبت به

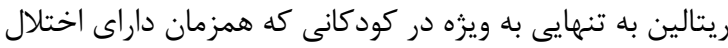
بيشفعالى و كمتوجهى هستند، مىشود. بنه

تشكر و قلرواذى

اين مقاله بركرفته از ياياننامه دوره دكترى تخصصى اطفال

junii B6. Curr Pharm Biotechnol. 2017;18(11):900-8. PMID: 29173159 DOI: $10.2174 / 1389201018666171122121350$

8. Wang LJ, Yu YH, Fu ML, Yeh WT, Hsu JL, Yang YH, et al. Attention deficit-hyperactivity disorder is associated with allergic symptoms and low levels of hemoglobin and serotonin. Sci Rep. 2018;8(1):10229. PMID: 29980754 DOI: $10.1038 / \mathrm{s} 41598-018-28702-5$

9. Bhagavan HN, Coleman M, Coursin DB. The effect of pyridoxine hydrochloride on blood serotonin and pyridoxal phosphate contents in hyperactive children. Pediatrics. 1975;55(3):437-41. PMID: 1143984

10. Coleman M, Steinberg G, Tippett J, Bhagavan H, Coursin D, Gross M, et al. A preliminary study of the effect of pyridoxine administration in a subgroup of hyperkinetic children: a double-blind crossover comparison with methylphenidate. Biol Psychiatry. 1979;14(5):741-51. PMID: 497303

11. Brenner A, Wapnir RA. A pyridoxine-dependent behavioral disorder unmasked by isoniazid. Am J Dis Child. 1978; 132(8):773-6. PMID: 150790 DOI: 10.1001/archpedi.1978. $\underline{02120330045011}$

12. Dolina S, Margalit D, Malitsky S, Rabinkov A. Attentiondeficit hyperactivity disorder (ADHD) as a pyridoxinedependent condition: Urinary diagnostic biomarkers. Med Hypotheses. 2014;82(1):111-6. PMID: 24321736 DOI: 10.1016/j.mehy.2013.11.018

13. Rucklidge JJ, Eggleston MJF, Darling KA, Stevens AJ, Kennedy MA, Frampton CM. Can we predict treatment 
response in children with ADHD to a vitamin-mineral supplement? An investigation into pre-treatment nutrient serum levels, MTHFR status, clinical correlates and demographic variables. Prog Neuropsychopharmacol Biol Psychiatry. 2019;89:181-92. PMID: 30217770 DOI: 10.1016/j.pnpbp.2018.09.007

14. Landaas ET, Aarsland TI, Ulvik A, Halmøy A, Ueland PM, Haavik J. Vitamin levels in adults with ADHD. BJP sych Open. 2016;2(6):377-84. PMID: 27990293 DOI: 10.1192/bjpo.bp.116.003491

15. Mousain-Bosc M, Roche M, Rapin J, Bali JP. Magnesium VitB6 intake reduces central nervous system hyperexcitability in children. $J$ Am Coll Nutr. 2004;23(5):545S-8S. PMID: 15466962 DOI: 10.1080/07315724.2004.10719400

16. Mousain-Bosc M, Roche M, Polge A, Pradal-Prat D, Rapin J, Bali J. Improvement of neurobehavioral disorders in children supplemented with magnesium-vitamin B6. Magnes Res.
2006;19(1):53-62. PMID: 16846101

17. Zarei Z. Preparation of polyvinyl alcohol / amino acid nanofiber wound dressings containing antibiotics. [Master Thesis]. Yazd: Azad University of Polymer Engineering; 2016. [In Persian]

18. Alizadeh H. A theoretical explanation on attention deficit/hyperactivity disorder: behavioral inhibition model and nature of self-control. J Excep Child. 2005;17(3):323-48. [In Persian]

19. Nogovitsina O, Levitina E. Effect of MAGNE-B6 on the clinical and biochemical manifestations of the syndrome of attention deficit and hyperactivity in children. Eksp Klin Farmakol. 2006;69(1):74-7. PMID: 16579066

20. Amen DG. Magnificent mind at any age: natural ways to unleash your brain's maximum potential. New York: Harmony; 2009. 